\title{
Association between level of suicide risk, characteristics of suicide attempts, and mental disorders among suicide attempters
}

\author{
Subin Park', Yeeun Lee ${ }^{2}$, Tak Youn ${ }^{3}$, Byung Soo Kim, Jong Ik Park ${ }^{5}$, Haesoo Kim ${ }^{6}$, Hyo Chu Lee 6
} and Jin Pyo $\mathrm{Hong}^{7^{*}}$ (D)

\begin{abstract}
Background: Past attempted suicide is a strong predictor of future suicide risk, but the risk varies among suicide attempters. Hence, it is important to clarify distinguishing features of lifetime attempters with a high level of current suicide risk for efficient preventive management.

Methods: We compared characteristics of suicide attempts and clinical characteristics among high-, moderate-, and low-risk attempters. Among the total of 6022 participants in the Korean Epidemiologic Catchment Area study, 193 reported a suicide attempt in their lifetime, 36 of which had high, 126 moderate, and 30 low levels of current suicide risk (1 incomplete response).

Results: High-risk suicide attempters had more past attempts compared with moderate- and low-risk suicide attempters. Suicide attempts were closely linked to a wide range of psychiatric comorbidities regardless of degree of current level of suicide risk, but the relative risk for having at least one mental disorder was the highest in high-risk attempters. Specifically, the relative risks for depressive disorder, anxiety disorders including obsessive-compulsive disorder and post-traumatic stress disorder, and substance use disorders were higher in high-risk attempters, and relative risk for somatoform disorder was higher in low-risk attempters than others.
\end{abstract}

Conclusions: Our findings indicated that special attention is required for suicide attempters with a history of repeated attempts and current mental disorders, particularly anxiety disorders.

Keywords: Suicide risk, Suicide attempt, Korea

\section{Background}

History of suicide attempts is one of the strongest predictors of future suicide risk [1, 2]. Suicide attempts tend to recur with each attempt showing increased capability of lethality [3]. Almost half of serious suicide attempters make another attempt within 5 years [4], and the risk of suicide completion was about tens to hundreds of times higher than in the general population [5-7]. Thus, it is essential to monitor surviving suicide attempters to prevent future suicidal behaviors. However, future suicide risk varies among attempters

\footnotetext{
* Correspondence: suhurhong@gmail.com

${ }^{7}$ Department of Psychiatry, Samsung Medical Center, Sungkyunkwan

University School of Medicine, 81 Irwon-ro, Gangnam-gu, Seoul 06351, South Korea

Full list of author information is available at the end of the article
}

given that not all past attempters repeat attempts and complete suicide [8]. Despite the relatively heightened risk, among individuals admitted to hospital for suicide attempts, $10-15 \%$ eventually complete suicide $[9,10]$, and, in a community-based sample, only $1.7 \%$ of participants with a history of attempts eventually completed suicide in the 17-year period [5]. Therefore, for efficient preventive management of past attempters, the multilevel factors associated with their increased suicide risks must be clarified.

Accumulated research has identified multiple factors that increase individuals' suicide risk. Socio-demographically, higher suicide risk is linked to fewer years of education, marital status of single or divorced, unemployment, lower income, and family history of suicide [11-16]. The presence of any psychiatric disorder increases suicide risk, 
including depressive and bipolar, anxiety, impulse-control, substance, and personality disorders $[1,11,16,17]$, and having more disorders increases the occurrence of suicide attempt [13]. Key risk factors vary across the progression from suicide ideation to plan to attempt [12]. Unique associations between each psychiatric disorder and different stages of suicidal behaviors (ideation, plans, and attempts) were noted; depression was more linked to suicide ideation but not suicide plan or attempt among those experiencing suicide ideation ("suicide ideators"), and, in contrast, symptoms accompanied by anxiety and agitation or impulsecontrol difficulty were more linked to an increased risk of plan or attempt among ideators [13]. Fewer studies have examined the risk factors that predict future suicidal behavior or completed suicide in past attempters. Risk factors included unemployment, living alone, psychiatric morbidities, more number of attempts, suicide methods used (lethality), and suicide intent of previous attempt in suicide attempters $[7-10,18,19]$.

However, this issue remains under-investigated using national studies from Asian countries; moreover, South Korea has a particularly high prevalence of suicide and suicidal behaviors compared to other countries [20] (i.e., the highest among Organization for Economic Cooperation and Development members [21]). Hence, we examined the association of suicide risk with a wide array of clinical, sociodemographic, and suicide-related variables among lifetime suicide attempters in a nationally representative sample of Koreans. We aimed to determine distinguishing features of high-risk suicide attempters as compared with moderate- and low-risk attempters.

\section{Methods}

\section{Sample}

We used data from the Korean Epidemiologic Catchment Area (KECA) study, which was conducted three times. In 2001 [22] and 2006 [23], the Korean version of the Composite International Diagnostic Interview (CIDI) was completed [24], and a follow-up to the KECA study was conducted in 2011. The KECA study was designed to evaluate the prevalence, correlates, and co-morbidities of mental disorders in the Diagnostic and Statistical Manual of Mental Disorders, Fourth Edition (DSM-IV) among Korean adults. Participants were selected using a stratified, multi-stage, clustered sample design based on a population census conducted by community registry offices in 2010 [25]. Individuals with the earliest birthday per selected household were randomly selected; 1682 of these refused to participate in the study, and, thus, 6022 individuals completed the face-to-face interview (78.7\% response rate) [26]. The study protocol was approved by the institutional review board of the Seoul National University College of Medicine. Written informed consent was obtained from all participants before participation in the study.

\section{Measurement}

\section{Suicide risk}

Suicide risk was assessed using the Suicide Module of the Korean version of the CIDI [24]. This module includes an assessment of the lifetime occurrence; age-ofonset; and latest occurrence of suicidal ideation, plans, and attempts [25,27]. We initially selected lifetime suicide attempters with the following question: "Have you ever attempted suicide?" We then assessed the current suicide risk of the lifetime suicide attempters. Because the Suicide Module of the CIDI does not have a scoring system to assess level of suicide risk, we scored based on the scoring system of the Suicidality Module of the Mini International Neuropsychiatric Interview (MINI) using the corresponding items [28, 29]: a history of lifetime suicide attempt ( 4 points), suicide attempts with intent to die or expectation of death (9 points), suicide attempts without intent to die (4 points), suicidal ideation in the past month (6 points), suicide plans in the past month (8 points), and suicide attempts in the past month (10 points). We classified the level of current suicide risk based on the sum of points of the questionnaire we used (1-8 points: low, 9-16 points: moderate, $\geq 17$ points: high). Among 193 participants who reported a suicide attempt in their lifetime, 36 were high-risk, 126 moderate-risk, and 30 low-risk. One participant was excluded from analysis due to an incomplete response.

\section{Characteristics of suicide attempt}

We collected information on the number of lifetime suicide attempts and family history of attempted and completed suicide. Precipitants for their attempted suicide were initially asked using the following dichotomous questions (i.e., Yes/No responses): Do you have any precipitant for attempted suicide? An individual with any precipitants for attempted suicide was asked to choose from the multiple choices of 1) aggravation of depression/anxiety, 2) conflict with family/friends/peers, 3) economic problems, 4) medical illness, 5) abuse/violence, 6) legal problems, 7) celebrity suicide, and 8) others [27].

\section{Comorbidity of DSM-IV disorders}

We used the CIDI [30] as a diagnostic assessment tool for psychiatric disorders. It is a fully structured diagnostic modality to establish psychiatric diagnoses based on definitions and criteria of the DSM-IV [31]. The Korean version of the CIDI [24] was later developed according to World Health Organization guidelines [32]. The inter-rater reliability, test/retest reliability, and validity of the Korean version of the CIDI showed kappa values ranging from 0.86 to $1.00,0.42$ to 0.89 , and 0.50 to 1.00 , respectively $[25,26]$. We used psychiatric disorders in the past 12 months in this study. 


\section{Other variables}

We used self-reported data from the 2011 KECA study for socio-demographic data, including gender, age, marital status, educational years, family income, marital status, and employment [26].

\section{Statistical analysis}

Weighted values were assigned to approximate the national population with respect to age and gender for each catchment area, using 2010 Korean census data, approved for use by the Korean National Statistical Office. We performed Pearson's chi-square test to compare gender, marital status, economic status, family history of suicide, and precipitants among high-, moderate-, and low-risk suicide attempters. Independent t-test was used to compare age, years of education, age at first attempt, and number of attempts among high-, moderate-, and low-risk suicide attempters. Multivariate logistic regression analyses were performed to evaluate the odds ratios and $95 \%$ confidence intervals of 12 -month comorbidities of mental disorders after controlling for age and gender. All statistical analyses were conducted using SPSS (version 21.0; SPSS Inc., Chicago, IL). A $p$-value $<.05$ was considered significant.

\section{Results}

Table 1 summarizes the comparisons among high-, moderate-, and low-risk attempters. High-risk attempters had the highest numbers of suicide attempts, and lowrisk attempters had the highest proportion of single attempts. There were no significant differences in family history and specific precipitants of suicide attempts by level of suicide risk.

Table 2 indicates the adjusted odds ratios of mental disorders in high-, moderate-, and low-risk attempters after controlling for age and gender. A total of $83.3 \%$ of highrisk attempters had at least one mental disorder in the previous year, which fulfilled DSM-IV diagnostic criteria [24]. This prevalence was significantly higher than that of moderate- (46.0\%) and low-risk attempters (36.7\%). Anxiety disorder was the most common mental disorder in suicide attempters regardless of suicide risk degree. Overall, compared to non-attempters, post-traumatic stress disorder (PTSD) and somatoform disorder were significantly associated with all suicide attempters with different extents of current suicide risk. On the other hand, depressive disorder, obsessive-compulsive disorder (OCD), specific phobia, and nicotine and alcohol use disorder were associated with only high- and moderate-risk attempters

Table 1 Comparison of Characteristics of Suicide Attempters by the Level of Suicidal Risk

\begin{tabular}{|c|c|c|c|c|c|c|}
\hline \multirow[t]{2}{*}{ Variables } & \multirow{2}{*}{$\begin{array}{l}\text { High-risk } \\
\text { attempters } \\
(N=36)\end{array}$} & \multirow{2}{*}{$\begin{array}{l}\text { Moderate-risk } \\
\text { attempters } \\
(N=126)\end{array}$} & \multirow{2}{*}{$\begin{array}{l}\text { Low-risk } \\
\text { attempters } \\
(N=30)\end{array}$} & \multicolumn{3}{|c|}{ Statistics } \\
\hline & & & & $\mathrm{F}$ & $p$ & Post-hoc \\
\hline Age & $44.73(15.31)$ & $43.21(15.77)$ & $36.95(13.73)$ & 2.47 & .087 & \\
\hline Education (years) & $10.79(3.96)$ & $11.55(4.10)$ & $13.01(3.00)$ & 2.72 & .068 & \\
\hline Age of first suicide attempt & $32.92(14.01)$ & $27.45(13.78)$ & $26.16(12.69)$ & 2.59 & .078 & \\
\hline \multirow[t]{2}{*}{ No. of attempts } & $3.79(5.25)$ & $2.06(1.90)$ & $1.64(1.04)$ & 6.52 & .002 & $\begin{array}{l}\text { High }>\text { Moderate }> \\
\text { Low }\end{array}$ \\
\hline & $\%$ & $\%$ & $\%$ & $x^{2}$ & p & Post-hoc \\
\hline Gender, female & 75.0 & 57.9 & 67.7 & 3.89 & .143 & \\
\hline Divorced/separated/widowed & 19.4 & 25.4 & 20.0 & 0.79 & .675 & \\
\hline Family income, $\leq 1000 \$$ & 62.7 & 57.9 & 52.9 & 0.87 & .647 & \\
\hline Employment, employed & 28.6 & 50.8 & 43.3 & 5.52 & .063 & \\
\hline$\%$ of single attempt & 36.1 & 56.0 & 63.3 & 5.85 & .053 & \\
\hline $\begin{array}{l}\% \text { of family history of suicide } \\
\text { attempt }\end{array}$ & 20.0 & 15.4 & 13.3 & 0.60 & .739 & \\
\hline$\%$ of family history of suicide & 11.1 & 13.7 & 3.4 & 2.42 & .298 & \\
\hline \multicolumn{7}{|l|}{ Precipitants } \\
\hline $\begin{array}{l}\text { Aggravation of depression/ } \\
\text { anxiety }\end{array}$ & 36.1 & 25.4 & 25.8 & 1.66 & .435 & \\
\hline $\begin{array}{l}\text { Conflict with family/friends/ } \\
\text { peers }\end{array}$ & 52.8 & 47.6 & 51.6 & 0.38 & .826 & \\
\hline Economic problems & 14.3 & 24.6 & 10.0 & 4.17 & .124 & \\
\hline Medical illness & 8.3 & 3.2 & 3.3 & 1.93 & .381 & \\
\hline $\begin{array}{l}\text { Other (i.e., abuse, violence, } \\
\text { legal problem, celebrity suicide) }\end{array}$ & 13.9 & 9.4 & 10.0 & 0.60 & .741 & \\
\hline
\end{tabular}




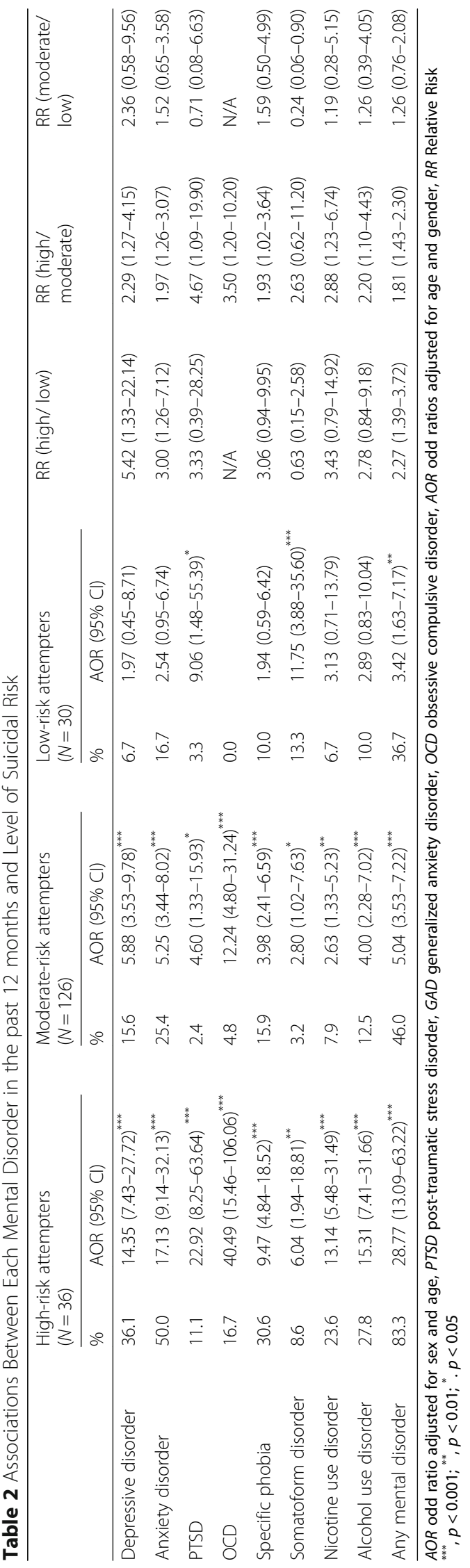


but not with low-risk attempters. Further, relative risk was significantly higher for depressive disorder, anxiety disorder, and OCD in high-risk attempters than in moderateand low-risk attempters. Relative risks for PTSD, specific phobia, and alcohol and nicotine use disorder were higher in high-risk attempters than in moderate-risk attempters. Relative risk for somatoform disorder was higher in lowrisk attempters than in moderate-risk attempters.

\section{Discussion}

In the present study, we investigated the association between level of suicide risk and characteristics of suicidal behaviors and mental disorders among lifetime suicide attempters. The results indicated that associated factors of suicide risk in attempters included number of lifetime suicide attempts and the presence of mental disorders.

The number of past suicide attempts varied across three groups of attempters in the order of high-risk > moderate-risk $>$ low-risk attempters, suggesting that the suicidal problems of high-risk attempters are the most chronic. Through the habitual and repeated process of suicide attempt, high-risk attempters may have acquired the ability to engage in supposedly fear-provoking suicidal behaviors with increased tolerance for physical pain and decreased fear of death, which are conditions for lethal suicidal behaviors $[3,33]$.

Although all groups of attempters had a relatively heightened family history of attempted (13.3-20.0\%) and completed suicide (3.4-13.7\%), consistent with wellestablished association between individual's suicidal behaviors and family history of suicide [34, 35], the family history did not differ by the extent of current suicide risk.

The close association of suicidal behaviors with a wide range of mental disorders is well-known [11, 17]. In line with prior findings, all lifetime attempters had a heightened risk of having one or more mental disorders. In particular, high-risk attempters had a relatively higher risk of any disorders with $83.3 \%$ presenting one or more diagnosable mental problems than other attempters. Among mental disorders, anxiety, depressive, and alcohol use disorders were the most prevalent among the suicide attempters in general, as reported in the US and cross-national findings $[11,12]$. The highest prevalence of anxiety disorders among attempters is compatible with the findings that disorders featured by severe anxiety and agitation predicted the progression from suicide ideation to plan or attempt [13].

Comparing three groups of attempters having different suicide risk, high-risk attempters had particularly higher odds of depressive disorder and anxiety disorders as higher risk of suicide completion was noted for such disorders in Tidemalm et al. [8]. Among anxiety symptoms, higher current suicide risk was linked to higher risk of OCD and PTSD. A recent epidemiological study [36] found that individuals with OCD showed a greater risk of attempted suicide and suicide completion largely independent of other mental disorders. Similarly, PTSD was recently identified as one of the strongest predictors of suicidal behaviors [11, 37, 38]. Our findings further suggested that lifetime suicide attempters with $\mathrm{OCD}$ and/or PTSD tend to have a high current suicidal risk whereas the odds of somatoform disorder were relatively higher among low-risk attempters. The association between somatoform disorder and suicidal behaviors has gained relatively less attention, but studies have reported that somatoform disorder or medically unexplained physical pain were significantly related to suicidal ideation and suicidal behaviors $[39,40]$. The current study added new findings that somatoform disorder is particularly more prevalent among lifetime suicidal attempters with low risk. Individuals with somatoform disorder may attempt suicide to get relief from distress associated with physical concerns or hopelessness derived from the belief that physical pain or concern would not improve [40], which could contribute to attempted suicide without strong desire to die. However, the underlying mechanism of high association of somatoform disorder with low-risk attempters was not addressed in the present study and requires further investigation.

The current study has several limitations. First, this was a cross-sectional study, and, thus, causal relationship between the degree of suicide risk and mental disorders could not be determined. Second, the degree of current suicide risk was not classified by standardized measurement. Additionally, since the study involved the administration of a largescale community survey, individual suicide behavior-ideation, plan, and attemptwas measured using a single-item and not standardized multi-item measures, which may limit the validity of measures. Lastly, suicide attempt may be under-reported because of stigma related to suicide attempts and concerns over its disclosure.

\section{Conclusions}

Our findings indicated the differentially associated factors of Korean suicide attempters with high-, moderate-, and low-level risks. Special attention is required for individuals who present associated features, such as history of repeated suicidal attempts and overall anxiety disorders.

\section{Abbreviations \\ CIDI: Composite International Diagnostic Interview; DSM-IV: Diagnostic and Statistical Manual of Mental Disorders, Fourth Edition; KECA: Korean Epidemiologic Catchment Area; MINI: Mini International Neuropsychiatric Interview; NRF: National Research Foundation of Korea; OCD: Obsessive- compulsive disorder; PTSD: Post-traumatic stress disorder}

\section{Acknowledgements}

We would like to thank the Ministry of Health and Welfare, Republic of Korea, 12 local investigators, and 79 interviewers who helped with this study. We also wish to thank all study participants for their time and commitment to the study. 


\section{Funding}

This work was supported by the research grant from the Korean Ministry of Health and Welfare and Korea Healthcare Technology R\&D project, Ministry of Health and Welfare, Republic of Korea [Grant number HI12C0035 and HI15C1072] and by the National Research Foundation of Korea (NRF) grant from the Korean Government (MSIP) [NRF- 2014R1A1A3049818]. The funders had no role in study design, data collection and analysis, and interpretation of data and in writing the manuscript.

\section{Availability of data and materials}

The datasets generated and analyzed during the current study are not publicly available because we are preparing an additional manuscript. However, they are available upon the reasonable request to corresponding author.

\section{Authors' contributions}

JPH designed the study. JPH, TY, BSK, and JIK took part in collecting data as members of the research project. SP performed the statistical analysis and wrote the draft of the paper. $Y L$ helped to write the draft of the paper and revised it. JPH, TY, BSK, JIK, HSK, and HCL interpreted data and revised the paper. All authors read and approved the final version of the manuscript.

\section{Ethics approval and consent to participate}

Institutional Review Board of Seoul National University College of Medicine provided ethical approval of this study. All participants were fully informed of the study objectives, and written consent was obtained from all participants.

\section{Consent for publication}

Not applicable.

\section{Competing interests}

The authors declare that they have no competing interests.

\section{Publisher's Note}

Springer Nature remains neutral with regard to jurisdictional claims in published maps and institutional affiliations.

\begin{abstract}
Author details
${ }^{1}$ Department of Research Planning, Mental Health Research Institute, National Center for Mental Health, 127 Yongma-ro, Gwangjin-gu, Seoul, South Korea. ${ }^{2}$ Department of Psychology, Korea University, 145 Anam-ro, Seongbuk-gu, Seoul, South Korea. ${ }^{3}$ Department of Psychiatry, Dongguk University Ilsan Hospital, 27 Dongguk-ro, Ilsandong-gu, Goyang, South Korea. ${ }^{4}$ Department of Psychiatry, Kyungpook National University, 807 Hoguk-ro, Buk-gu, Daegu, South Korea. ${ }^{5}$ Department of Psychiatry, College of Medicine, Kangwon National University, 156 Baengnyeong-ro, Chuncheon, Gangwon-do, South Korea. ${ }^{6}$ Department of Psychiatry, Samsung Medical Center, 81 Irwon-ro, Gangnam-gu, Seoul, South Korea. ${ }^{7}$ Department of Psychiatry, Samsung Medical Center, Sungkyunkwan University School of Medicine, 81 Irwon-ro, Gangnam-gu, Seoul 06351, South Korea.
\end{abstract}

\section{Received: 24 February 2017 Accepted: 28 March 2018}

\section{Published online: 11 April 2018}

\section{References}

1. Brown GK, Beck AT, Steer RA, Grisham JR. Risk factors for suicide in psychiatric outpatients: a 20-year prospective study. J Consult Clin Psychol. 2000;68(3):371-7.

2. Harris EC, Barraclough B. Suicide as an outcome for mental disorders. A meta-analysis. Br J Psychiatry. 1997;170(3):205.

3. Van Orden KA, Witte TK, Cukrowicz KC, Braithwaite S, Selby EA, Joiner TE. The interpersonal theory of suicide. Psychol Rev. 2010;117(2):575-600.

4. Beautrais AL. Further suicidal behavior among medically serious suicide attempters. Suicide Life Threat Behav. 2004;34(1):1-11.

5. Kuo W-H, Gallo JJ. Completed suicide after a suicide attempt. Am J Psychiatr. 2005;162(3):633.

6. Owens D, Horrocks J, House A. Fatal and non-fatal repetition of self-harm. $\mathrm{Br}$ J Psychiatry. 2002;181(3):193.

7. Christiansen E, Frank Jensen B. Risk of repetition of suicide attempt, suicide or all deaths after an episode of attempted suicide: a register-based survival analysis. Aust N Z J Psychiatry. 2007;41(3):257-65.
8. Tidemalm D, Långström N, Lichtenstein P, Runeson B. Risk of suicide after suicide attempt according to coexisting psychiatric disorder: Swedish cohort study with long term follow-up. BMJ. 2008;337:a2205.

9. Suominen K, Isometsä E, Suokas J, Haukka J, Achte K, Lönnqvist J. Completed suicide after a suicide attempt: a 37-year follow-up study. Am J Psychiatr. 2004;161(3):562-3.

10. Tejedor MC, Diaz A, Castillón JJ, Pericay JM. Attempted suicide: repetition and survival findings of a follow-up study. Acta Psychiatr Scand. 1999;100(3):205-11.

11. Nock MK, Borges G, Bromet EJ, Alonso J, Angermeyer M, Beautrais A, Bruffaerts R, Chiu WT, De Girolamo G, Gluzman S. Cross-national prevalence and risk factors for suicidal ideation, plans and attempts. Br J Psychiatry. 2008;192(2):98-105.

12. Kessler RC, Borges G, Walters EE. Prevalence of and risk factors for lifetime suicide attempts in the national comorbidity survey. Arch Gen Psychiatry. 1999;56(7):617-26.

13. Nock MK, Hwang I, Sampson NA, Kessler RC. Mental disorders, comorbidity and suicidal behavior: results from the National Comorbidity Survey Replication. Mol Psychiatry. 2010;15(8):868-76.

14. Phillips MR, Yang G, Zhang Y, Wang L, Ji H, Zhou M. Risk factors for suicide in China: a national case-control psychological autopsy study. Lancet. 2002; 360(9347):1728-36.

15. Qin P, Agerbo E, Mortensen PB. Suicide risk in relation to socioeconomic, demographic, psychiatric, and familial factors: a National Register-Based Study of all suicides in Denmark, 1981-1997. Am J Psychiatr. 2003;160(4):765-72.

16. Petronis KR, Samuels JF, Moscicki EK, Anthony JC. An epidemiologic investigation of potential risk factors for suicide attempts. Soc Psychiatry Psychiatr Epidemiol. 1990;25(4):193-9.

17. Cavanagh JTO, Carson AJ, Sharpe M, Lawrie SM. Psychological autopsy studies of suicide: a systematic review. Psychol Med. 2003;33(3):395-405.

18. Hall RCW, Platt DE, Hall RCW. Suicide risk assessment: a review of risk factors for suicide in 100 patients who made severe suicide attempts. Psychosomatics. 1999;40(1):18-27

19. Beghi M, Rosenbaum JF, Cerri C, Cornaggia CM. Risk factors for fatal and nonfatal repetition of suicide attempts: a literature review. Neuropsychiatr Dis Treat. 2013;9:1725-36.

20. Jeon HJ, Lee J-Y, Lee YM, Hong JP, Won S-H, Cho S-J, Kim J-Y, Chang SM, Lee D, Lee HW, et al. Lifetime prevalence and correlates of suicidal ideation, plan, and single and multiple attempts in a Korean Nationwide study. J Nerv Ment Dis. 2010;198(9):643-6.

21. OECD. "Suicide", in health at a glance 2015. Paris: OECD Publishing; 2015.

22. Cho MJ, Kim J-K, Jeon HJ, Suh T, Chung I-W, Hong JP, Bae J-N, Lee D-W, Park JI, Cho S-J, et al. Lifetime and 12-month prevalence of DSM-IV psychiatric disorders among Korean adults. J Nerv Ment Dis. 2007;195(3):203-10.

23. Cho MJ, Chang SM, Lee YM, Bae A, Ahn JH, Son J, Hong JP, Bae JN, Lee DW, Cho S-J, et al. Prevalence of DSM-IV major mental disorders among Korean adults: a 2006 National Epidemiologic Survey (KECA-R). Asian J Psychiatr. 2010;3(1):26-30.

24. Cho MJ, Hahm BJ, Suh DW, Hong JP, Bae JN, Kim JK, Lee DW, Cho SJ. Development of a Korean version of the composite international diagnostic interview (K-CIDI). J Korean Neuropsychiatr Assoc. 2002;41(1):123-37.

25. Park S, Hong JP, Bae JN, Cho S-J, Lee D-W, Lee J-Y, Chang SM, Jeon HJ, Hahm B-J, Lee YM, et al. Impact of childhood exposure to psychological trauma on the risk of psychiatric disorders and somatic discomfort: single vs. multiple types of psychological trauma. Psychiatry Res. 2014;219(3):443-9.

26. Cho MJ, Seong SJ, Park JE, Chung I-W, Lee YM, Bae A, Ahn JH, Lee D-W, Bae JN, Cho S-J, et al. Prevalence and correlates of DSM-IV mental disorders in south Korean adults: the Korean epidemiologic catchment area study 2011. Psychiatry Investig. 2015;12(2):164-70.

27. Jeon HJ, Lee J-Y, Lee YM, Hong JP, Won S-H, Cho S-J, Kim J-Y, Chang SM, Lee HW, Cho MJ. Unplanned versus planned suicide attempters, precipitants, methods, and an association with mental disorders in a Koreabased community sample. J Affect Disord. 2010;127(1):274-80.

28. Lecrubier $Y$, Sheehan DV, Weiller E, Amorim P, Bonora I, Harnett Sheehan K, Janavs J, Dunbar GC. The Mini International Neuropsychiatric Interview (MINI). A short diagnostic structured interview: reliability and validity according to the CIDI. Eur Psychiatry. 1997;12(5):224-31.

29. Yoo S-W, Kim Y-S, Noh J-S, Oh K-S, Kim C-H, NamKoong K, Chae J-H, Lee GC, Jeon S-I, Min K-J. Validity of Korean version of the mini-international neuropsychiatric interview. Anxiety Mood. 2006;2(1):50-55. 
30. World Health Organization. Composite international diagnostic interview (CIDI), version 1.0. In: Composite International Diagnostic Interview (CIDI), Version 10. edn. 1993.

31. American Psyciatric Association. Diagnostic and statistical manual of mental disorders. Forth edition. Washington, DC: American Psychiatric Association; 1994.

32. World Health Organization. CIDI, core version 2.1 Interviewer's manual. Geneva: World Health Organization; 1997. p. 1-114.

33. Joiner T. Why people die by suicide. Cambridge: Harvard University Press; 2007.

34. Qin P, Agerbo E, Mortensen PB. Suicide risk in relation to family history of completed suicide and psychiatric disorders: a nested case-control study based on longitudinal registers. Lancet. 2002;360(9340):1126-30.

35. Runeson B, Åsberg M. Family history of suicide among suicide victims. Am J Psychiatr. 2003;160(8):1525-6.

36. Fernandez de la Cruz L, Rydell M, Runeson B, D'Onofrio BM, Brander G, Ruck C, Lichtenstein P, Larsson H, Mataix-Cols D. Suicide in obsessive-compulsive disorder: a population-based study of 36[thinsp]788 Swedish patients. Mol Psychiatry. 2016;22(11):1626-1632.

37. Wilcox HC, Storr CL, Breslau N. Posttraumatic stress disorder and suicide attempts in a community sample of urban american young adults. Arch Gen Psychiatry. 2009;66(3):305-11.

38. Panagioti M, Gooding PA, Tarrier N. A meta-analysis of the association between posttraumatic stress disorder and suicidality: the role of comorbid depression. Compr Psychiatry. 2012;53(7):915-30.

39. Park S, Cho MJ, Seong S, Shin SY, Sohn J, Hahm B-J, Hong JP. Psychiatric morbidities, sleep disturbances, suicidality, and quality-of-life in a community population with medically unexplained pain in Korea. Psychiatry Res. 2012;198(3):509-15.

40. Wiborg JF, Gieseler D, Fabisch AB, Voigt K, Lautenbach A, Löwe B. Suicidality in primary care patients with somatoform disorders. Psychosom Med. 2013; 75(9):800-6.

\section{Submit your next manuscript to BioMed Central and we will help you at every step:}

- We accept pre-submission inquiries

- Our selector tool helps you to find the most relevant journal

- We provide round the clock customer support

- Convenient online submission

- Thorough peer review

- Inclusion in PubMed and all major indexing services

- Maximum visibility for your research

Submit your manuscript at www.biomedcentral.com/submit 